\title{
Scintillators with Potential to Supersede Lanthanum Bromide
}

\author{
N.J. Cherepy, * S.A. Payne, S.J. Asztalos, G. Hull, J.D. Kuntz, T. Niedermayr, S. Pimputkar, \\ J.J. Roberts, R.D. Sanner, T.M. Tillotson, E. van Loef, C.M. Wilson, K.S. Shah, \\ U.N. Roy, R. Hawrami, A. Burger, L.A. Boatner, W.-S. Choong and W.W. Moses
}

\begin{abstract}
New scintillators for high-resolution gamma ray spectroscopy have been identified, grown and characterized. Our development efforts have focused on two classes of high light yield materials: Europium-doped alkaline earth halides and Cerium-doped garnets. Of the halide single crystals we have grown by the Bridgman method- $\mathrm{SrI}_{2}, \mathrm{CaI}_{2}, \mathrm{SrBr}_{2}, \mathrm{BaI}_{2}$ and $\mathrm{BaBr}_{2}-\mathrm{SrI}_{2}$ is the most promising. $\mathrm{SrI}_{2}(\mathrm{Eu})$ emits into the $\mathrm{Eu}^{2+}$ band, centered at $435 \mathrm{~nm}$, with a decay time of $1.2 \mu \mathrm{s}$ and a light yield of up to 115,000 photons/MeV. It offers energy resolution better than $3 \%$ FWHM at $662 \mathrm{keV}$, and exhibits excellent light yield proportionality. Transparent ceramics fabrication allows production of Gadolinium- and Terbium-based garnets which are not growable by melt techniques due to phase instabilities. While scintillation light yields of Cerium-doped ceramic garnets are high, light yield non-proportionality and slow decay components appear to limit their prospects for high energy resolution. We are developing an understanding of the mechanisms underlying energy dependent scintillation light yield non-proportionality and how it affects energy resolution. We have also identified aspects of optical design that can be optimized to enhance energy resolution.
\end{abstract}

Index Terms - Scintillators, strontium iodide, ceramic scintillators, gamma ray detectors

\section{INTRODUCTION}

Use of gamma ray spectroscopy for radioisotope identification requires pushing the limits of energy resolution, and is also enhanced by a high effective atomic number of the detector material. The commercial inorganic scintillator currently providing the highest energy resolution is $\mathrm{LaBr}_{3}(\mathrm{Ce})$, of $\sim 2.6 \%$ at $662 \mathrm{keV}[1-3]$, but it is highly hygroscopic,

Manuscript received June 31, 2008. This work was supported by the Domestic Nuclear Detection Office in the Department of Homeland Security (Alan Janos) and by the National Nuclear Security Administration, Office of Nonproliferation Research and Development (NA-22, Robert Mayo) of the U.S.DOE under Contract No. DE-AC02-05CH11231, and this work was performed under the auspices of the U.S. DOE by Lawrence Livermore National Laboratory under Contract DE-AC52-07NA27344. Oak Ridge National Laboratory is managed for the U.S DOE by UT-Battelle under contract DE-AC05-00OR22725.

N.J. Cherepy S.A. Payne, S.J. Asztalos, G. Hull, J.D. Kuntz, T. Niedermayr, S. Pimputkar, J.J. Roberts, R.D. Sanner, T.M. Tillotson are with Lawrence Livermore National Laboratory, Livermore, CA 94550 (phone: +1925-424-3492; fax: +1-925-423-6394; e-mail: cherepy1@1lnl.gov).

E. van Loef, C.M. Wilson and K.S. Shah are with Radiation Monitoring Devices, Watertown, MA (e-mail: kanaishah@yahoo.com).

U.N. Roy, R. Hawrami and A. Burger are with Fisk University, Nashville, TN (e-mail: aburger@fisk.edu).

L.A. Boatner is with Oak Ridge National Laboratory, Oak Ridge, TN (email: 1b4@ornl.gov).

W.W. Moses and W.-S. Choong are with Lawrence Berkeley National Laboratory, Berkeley, CA (e-mail: wwmoses@llbl.gov). possesses intrinsic radioactivity due to the presence of primordial ${ }^{138} \mathrm{La}$, and its crystal growth is still challenging. Energy resolution of $\sim 2 \%$ at $662 \mathrm{keV}$ is desired for assignments of gamma ray lines in a typical spectrum, while intrinsic radioactivity interferes with low count rate measurements, especially for large detector volumes. Finally, the ease of crystal growth is directly correlated with cost of manufacture of large crystals useful for detection of weak sources.

To identify new scintillator materials with potential to supersede the performance and cost metrics of $\mathrm{LaBr}_{3}(\mathrm{Ce})$, we use a "directed search methodology," which is distinguished from the "combinatorial approach" by aggressively downselecting candidates based on criteria and available information. For first round qualification, criteria are: (1) effective atomic number $\left(Z_{\text {eff }}\right)$ equivalent to or higher than $\mathrm{LaBr}_{3}(\mathrm{Ce})$, for efficient photoelectric effect, (2) no/low intrinsic radioactivity for low background, and (3) expected radioluminescence light yield adequate to achieve energy resolution of $2 \%$. Once high-Z, high light yield materials are identified, we evaluate their prospects for good light yield proportionality, ease of crystal growth, lack of confounding phase transitions, low deliquescence, favorable optical properties, dominant decay time of $<3 \mu$ s (to avoid signal pileup with standard shaping electronics) and photodetector spectral match. Figure 1 shows how the periodic table can be analyzed such that only compounds containing at least one of the encircled species are considered, yielding a reasonably short candidate list of materials for growth and evaluation.

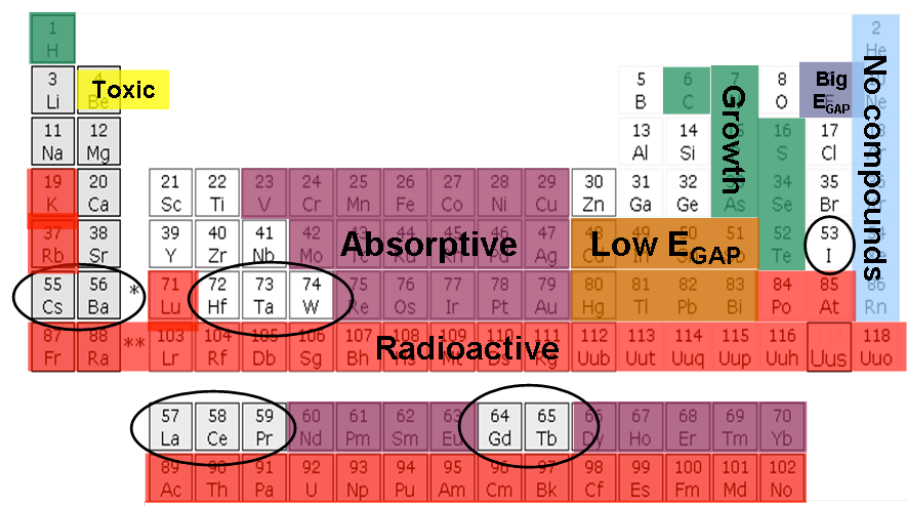

Fig. 1. Selection of candidate scintillators for gamma ray spectroscopy is straightforward, as only a few high- $Z$ elements (shown encircled) are nonradioactive, not optically absorptive and produce growable compounds. 
Among the candidates thus identified, we have pursued a focused effort toward evaluating the simple binary alkaline earth halides, since $\mathrm{CaI}_{2}(\mathrm{Eu})$ is well-known to exhibit an excellent light yield $(\sim 100,000 \mathrm{Ph} / \mathrm{MeV})$ while also being difficult to grow due to its layered structure [4]. In contrast, $\mathrm{SrBr}_{2}, \mathrm{SrI}_{2}, \mathrm{BaBr}_{2}$ and $\mathrm{BaI}_{2}$ are readily growable orthorhombic crystals [5-9]. We previously reported that $\operatorname{SrI}_{2}(\mathrm{Eu})$ crystals doped with $0.5 \%$ Eu produce $>80,000 \mathrm{Ph} / \mathrm{MeV}$, can provide energy resolution of $3.7 \%$ at $662 \mathrm{keV}$, and exhibit excellent light yield proportionality. ${ }^{5}$ Meanwhile, the best performance we have found for $\mathrm{BaI}_{2}(\mathrm{Eu})$ is a light yield of $>30,000$ $\mathrm{Ph} / \mathrm{MeV}$, and energy resolution of $\sim 8 \%$ [5]. We report here on our further studies of the scintillation of europium-doped alkaline earth halides.

The $\mathrm{BiI}_{3}$-structure iodides $\mathrm{YI}_{3}(\mathrm{Ce}), \mathrm{GdI}_{3}(\mathrm{Ce}), \mathrm{LuI}_{3}(\mathrm{Ce})$ are high-Z, high light yield materials described by Shah and coworkers recently [10]. While light yields are in the 100,000 $\mathrm{Ph} / \mathrm{MeV}$ range and the principal decays were measured to be $<100 \mathrm{~ns}$, the optical and mechanical properties of these crystals are severely impugned by their layered, easily cleaved structure. Other single crystal candidates include high- $\mathrm{Z}$ elpasolites and related complex halide crystals, such as $\mathrm{Cs}_{2} \mathrm{CeBr}_{5}$ and $\mathrm{Cs}_{2} \mathrm{LiYCl}_{6}$, offering light yields which may be adequate for high energy resolution [11,12].

In addition to single crystals, we have considered the potential of transparent ceramic oxides as gamma spectroscopy scintillators. Transparent ceramics are polycrystalline optics formed by consolidation of nanocrystalline precursors into a fully dense solid, with typical grain sizes of 1-10 microns. Cubic crystal structures are preferred for transparent ceramics in order to minimize optical scatter. Therefore, we synthesized powders and ceramics of many high- $Z$ cubic oxide candidates, finding that few of them activated with Cerium to produce high light yields (Table I). Lanthanide Aluminum Garnets doped with Cerium were identified as the most promising, and we have focused our development efforts on this family. Strontium and Barium Hafnate scintillator ceramics with moderate light yields have been reported [13]. Lutetium Aluminum Garnet (LuAG:Ce), Gadolinium Aluminum Garnet (GAG:Ce) and Terbium Aluminum Garnet (TAG:Ce) feature high density, high effective atomic number (e.g. $\rho=6.7 \mathrm{~g} / \mathrm{cm}^{3}$ and $Z_{\text {eff }}=58.9$ for LuAG), and good light yields [14-16]. Garnet single crystals are typically grown by the Czochralski method, and production of large-sized optics is therefore expensive. Transparent polycrystalline ceramics not only allow production costs to be substantially reduced, but permits fabrication of compositions that are incongruently melting and therefore unobtainable via melt growth. Furthermore, activator concentration and uniformity can be considerably increased over melt-grown crystals.

LuAG:Ce scintillators have been described [17], but the presence of intrinsic radioactivity arising from the beta and gamma emission from ${ }^{176} \mathrm{Lu}(2.59 \%$ natural abundance $)$ is an undesirable interference of $\sim 200$ decays $/ \mathrm{s}-\mathrm{cm}^{3}$. One paper on single crystal Ce-doped Gadolinium Scandium Aluminum Garnet reported energy resolution of $12.5 \%$ at $662 \mathrm{keV}$ [18].
YAG:Ce ceramics have been demonstrated to offer energy resolution in of $\sim 7 \%$ [19], but its $Z_{\text {eff }}$ is too low for efficient photoelectric interaction.

TABLE I

CUBIC OXIDES STUDIED FOR TRANSPARENT CERAMICS FABRICATION

\begin{tabular}{|c|c|c|}
\hline Structure type & Illustrative Material & Status \\
\hline Garnet & $\begin{array}{l}\mathrm{Gd}_{3} \mathrm{Sc}_{2} \mathrm{Al}_{3} \mathrm{O}_{12}- \\
\text { GSAG }\end{array}$ & High transparency, good LY \\
\hline Perovskite & $\mathrm{SrHfO}_{3}-\mathrm{SHO}$ & $\begin{array}{l}\text { High transparency, modest } \\
\text { LY }\end{array}$ \\
\hline Defect Fluorite & $\mathrm{Y}_{3} \mathrm{TaO}_{7}$ & Non-luminescent with Ce \\
\hline Pyrochlore & $\mathrm{La}_{2} \mathrm{Hf}_{2} \mathrm{O}_{7}-\mathrm{LHO}$ & Non-luminescent with $\mathrm{Ce}$ \\
\hline Bixbyite & $\mathrm{Gd}_{2} \mathrm{O}_{3}$ & Non-luminescent with $\mathrm{Ce}$ \\
\hline Defect Fluorite & $\mathrm{HfO}_{2}-\mathrm{Y}_{2} \mathrm{O}_{3}$ & Non-luminescent with $\mathrm{Ce}$ \\
\hline Simple Cubic & $\mathrm{BaO}$ & Excessively hygroscopic \\
\hline
\end{tabular}

Ultimately, the energy resolution from scintillator detectors will reach achievable limits with the use of scintillators exhibiting the most proportional and highest light yields, and when light collection and detection are optimized. For this reason, a unique instrument, the Scintillation Light Yield Nonproportionality Characterization Instrument (SLYNCI), has been set up to characterize scintillator materials and gain insight into the mechanisms affecting light yield [20,21], and we are developing analytical tools to deduce the nonproportionality contribution to energy resolution from SLYNCI data. Finally, we have identified several technological advances to maximize optical transfer and uniformity that, combined with high light yield and proportional scintillator materials, could lead to a commercial $2 \%$ resolution scintillator detector [22].

\section{AlKALINE EARTH HALIDES}

\section{A. Calcium Iodide and Strontium Bromide}

Calcium Iodide and Strontium Bromide crystals were grown via the Bridgman method at Radiation Monitoring Devices (RMD), with $0.5 \%$ Europium doping. The $\mathrm{CaI}_{2}(\mathrm{Eu})$ crystal is substantially opaque due to optical scatter, considered unavoidable due to its platelet crystal structure. Its radioluminescence spectrum was measured at 110,000 $\mathrm{Ph} / \mathrm{MeV}$, and is shown in Figure 2.

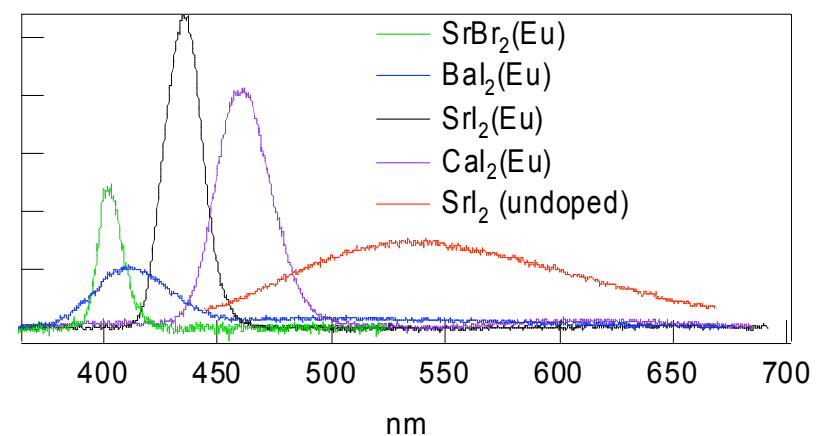

Fig. 2. Beta-excited radioluminescence spectra of several alkaline earth halide crystals. Europium-doped crystals exhibit blue emission, while undoped $\mathrm{SrI}_{2}$ produces a broad band. Spectra have been corrected for photodetector sensitivity. 
$\mathrm{SrBr}_{2}(\mathrm{Eu})$ is an orthorhombic crystal with good optical properties, however, its light yield so far is low $(\sim 25,000$ $\mathrm{Ph} / \mathrm{MeV})$. All radioluminescence spectra reported herein were acquired with a ${ }^{90} \mathrm{Sr}{ }^{90} \mathrm{Y}$ source $(\sim 1 \mathrm{MeV}$ average beta energy) and emission spectra were collected into a Princeton Instruments/Acton Spec 10 spectrograph coupled to a thermoelectrically cooled CCD camera.

\section{B. Strontium Iodide}

Undoped Strontium Iodide was grown and zone-refined at Fisk University. The luminescence spectrum, shown in Figure 2 , is unchanged between pure and impure segments of the boule, however, the pulse height spectrum of the purer section is slightly higher. Pulse height measurements, shown in Figure 3, were acquired using a Hamamatsu R329EGP PMT (QE at $550 \mathrm{~nm}$ of $15 \%$ ). The signals from the PMT anode were collected on a $500 \Omega$ resistor, shaped with a Tennelec TC 244 spectroscopy amplifier (shaping time of $8 \mu \mathrm{s}$ ) and then recorded with the Amptek MCA8000-A multi-channel analyzer. The emission is likely due to self-trapped excitons.

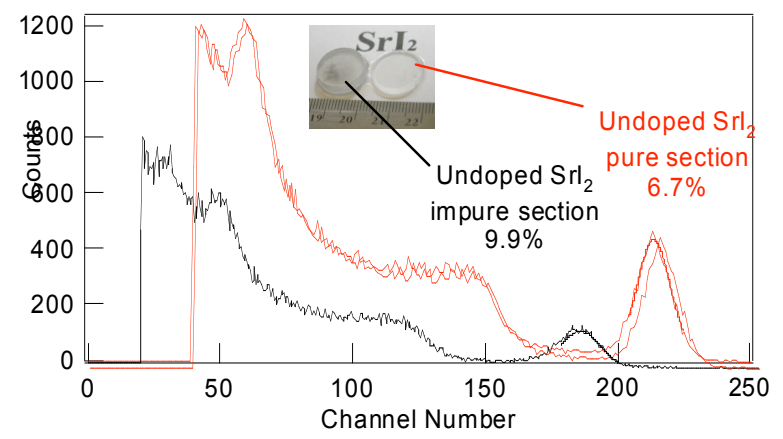

Fig. 3. Energy resolution of undoped Strontium Iodide crystals improves with purity, but is limited by the slow overall decay time and the luminescence spectrum which is poorly matched to standard PMTs.

A crystal of Strontium Iodide doped with $6 \%$ Europium was grown at Oak Ridge National Laboratory (ORNL) and its radioluminescence is also shown in Figure 2. In comparison to previous $\mathrm{SrI}_{2}$ crystals with $0.5 \% \mathrm{Eu}$ [5], the 6\%-doped crystal has a higher light yield, and superior energy resolution. Pulse height spectra ofSrI $2(\mathrm{Eu})$ compared to $\mathrm{LaBr}_{3}(\mathrm{Ce})$ acquired at $662 \mathrm{keV}$ using a Hamamatsu R980 bialkali PMT $(\mathrm{QE}=30 \%$ in $380-420 \mathrm{~nm}$ range $)$ and $8 \mu$ s shaping time are shown in Figure 4.

An intriguing factor appears relevant to the excellent performance of $\mathrm{SrI}_{2}(\mathrm{Eu})$. That is, the lattice constants for $\mathrm{SrI}_{2}$ and $\mathrm{EuI}_{2}$ are nearly identical $[24,25]$, thus permitting high, uniform doping of Eu in $\mathrm{SrI}_{2}$. Other favorable aspects of $\mathrm{SrI}_{2}$ include its low melting point, $538^{\circ} \mathrm{C}$, and its orthorhombic crystal structure, which will likely be readily growable to large sizes.

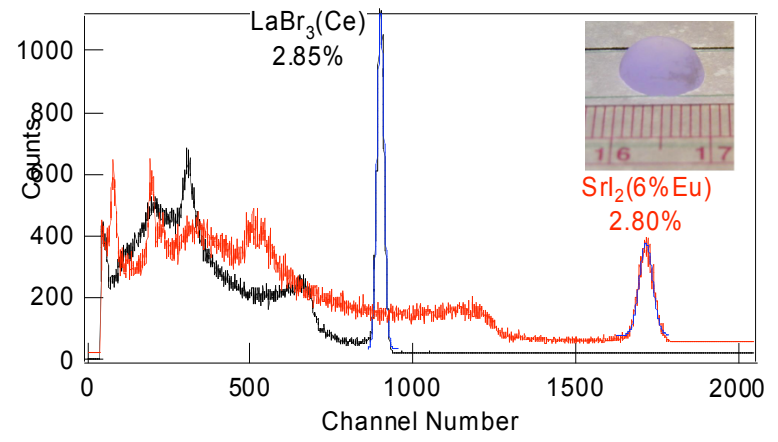

Fig. 4. Energy resolution of the Strontium Iodide crystal shown in the photo inset, reveals comparable energy resolution to that of $\mathrm{LaBr}_{3}(\mathrm{Ce})$.

\section{Barium Iodide and Barium Bromide}

Many crystals of Barium Iodide were grown at RMD, Fisk University and ORNL and characterized at LLNL $[5,7]$. The radioluminescence of $\mathrm{BaI}_{2}(\mathrm{Eu})$ typically shows both a longwave band, similar to that seen in undoped $\mathrm{SrI}_{2}$, as well as the $\mathrm{Eu}$ band in the blue (Figure 2). The long-wave band, thought to be due to impurity-mediated and related to self-trapped exciton luminescence, is reduced as the Eu doping level is increased. However, even for crystals exhibiting only Eu luminescence, gamma light yields and energy resolution so far are modest (see Table II) [5]. Barium Bromide crystals were grown doped with $\mathrm{Eu}$, (at Fisk University) and have been reported by Selling, et al. but light yields are $<30,000 \mathrm{Ph} / \mathrm{MeV}$ [8]. While it may be possible for the performance of $\mathrm{BaI}_{2}$ and $\mathrm{BaBr}_{2}$ to be improved, the intrinsic mismatch in metal-halide lattice constants compared to those of the corresponding Euhalide may hinder doping, and hence reduce light yields, or other energetic considerations, such as relative positions of the $\mathrm{Eu}^{2+}$ states within the bandgap may limit light yields. For

TABLE II

SCINTILLATION PROPERTIES OF ALKALINE EARTH HALIDE CRYSTALS

\begin{tabular}{|c|c|c|c|c|c|c|c|c|}
\hline Scintillator & $\begin{array}{c}\rho \\
\left(\mathrm{g} / \mathrm{cm}^{3}\right)\end{array}$ & $\mathrm{Z}_{\mathrm{eff}}{ }^{\mathrm{a}}$ & $\begin{array}{c}\text { Emission } \\
\text { Peak } \\
(\mathrm{nm})\end{array}$ & $\begin{array}{c}\text { Estimated } \\
\text { Band Gap, } \mathrm{E}_{\mathrm{g}}{ }^{\mathrm{b}} \\
(\mathrm{eV})\end{array}$ & $\begin{array}{c}\text { Theoretical } \\
\text { Maximum LY }^{\mathrm{d}} \\
(\mathrm{Ph} / \mathrm{MeV})\end{array}$ & $\begin{array}{c}\text { Measured } \beta \text { LY } \\
(\mathrm{Ph} / \mathrm{MeV})\end{array}$ & $\begin{array}{c}\text { Measured } \gamma \mathrm{LY} \\
(\mathrm{Ph} / \mathrm{MeV})\end{array}$ & $\begin{array}{l}\text { Measured } \\
\text { Resolution } \\
(662 \mathrm{keV})\end{array}$ \\
\hline $\mathrm{SrI}_{2}$ undoped & 4.549 & 49.4 & 560 & $3.7^{\mathrm{c}}$ & 111,000 & 62,000 & 22,000 & $6.7 \%$ \\
\hline $\mathrm{SrBr}_{2}(\mathrm{Eu})$ & 4.216 & 36.1 & 410 & 4.0 & 100,000 & 25,000 & 20,000 & $7 \%$ \\
\hline $\mathrm{BaI}_{2}(\mathrm{Eu})$ & 5.150 & 54.1 & 422 & 3.9 & 103,000 & 40,000 & 35,000 & $8 \%$ \\
\hline $\mathrm{BaBr}_{2}(\mathrm{Eu})$ & 4.781 & 45.5 & 406 & 4.1 & 98,000 & 22,000 & $16,000^{\mathrm{e}}$ & $11 \%^{\mathrm{e}}$ \\
\hline
\end{tabular}

${ }^{a} Z_{\text {eff }}$ calculated as the weighted average of component elements to the $4^{\text {th }}$ power.

${ }^{\mathrm{b}}$ Band gaps estimated from optical absorption and luminescence spectra

${ }^{c}$ Calculated via Local Density Approximation from ref 26.

${ }^{\mathrm{d}}$ Using $L Y_{\mathrm{th}}=10^{6} / \beta \mathrm{E}_{\mathrm{g}}$ and assuming $\beta=2.5$ for all materials

from Ref. 8 
example, the $\mathrm{Eu}^{2+}$ excited state in $\mathrm{BaI}_{2}$ may be too close to the conduction band to compete effectively with residual shallow traps, while this matter is resolved in $\mathrm{SrI}_{2}$ since the $\mathrm{Eu}^{2+}$ excited state is slightly lower with respect to the conduction band.

In summary, of the alkaline earth halides, $\operatorname{SrI}_{2}(\mathrm{Eu})$ appears most promising due to its very high light yield, good optical properties, ease of growth, high achievable doping with $\mathrm{Eu}^{2+}$, $Z_{\text {eff }}$ higher than $\mathrm{LaBr}_{3}(\mathrm{Ce})$, excellent light yield proportionality and demonstrated energy resolution of $2.8 \%$ at $662 \mathrm{keV}$. $\mathrm{CaI}_{2}$ is ungrowable in large sizes and $\mathrm{SrBr}_{2}$ has a low $Z_{\text {eff }}$, while $\mathrm{BaI}_{2}$ and $\mathrm{BaBr}_{2}$ have not demonstrated adequate light yields for high energy resolution.

\section{TRANSPARENT CERAMIC SCINTILLATORS}

\section{A. Lutetium and Terbium Garnets}

At LLNL we pursued a simple universal process for fabrication of transparent ceramics based on a flame spray pyrolysis (FSP) production method for nanoparticle feedstock. The FSP nanoparticles are formed into a green body, vacuum sintered, then hot-isostatic pressed into optically transparent parts [27]. Figure 5 shows that a $\operatorname{LuAG}(\mathrm{Ce})$ single crystal (nominal doping of $1 \% \mathrm{Ce}$ ), and a $\operatorname{LuAG}(\mathrm{Ce})$ ceramic $(0.02$ atomic fraction $\mathrm{Ce}$, substituting for $\mathrm{Lu}$ ) provide similar light yields. The inset photo in Figure 5 shows the excellent transparency of our transparent ceramics (scatter mean free path $>1 \mathrm{~cm}$ is typically achieved for pure phase materials).

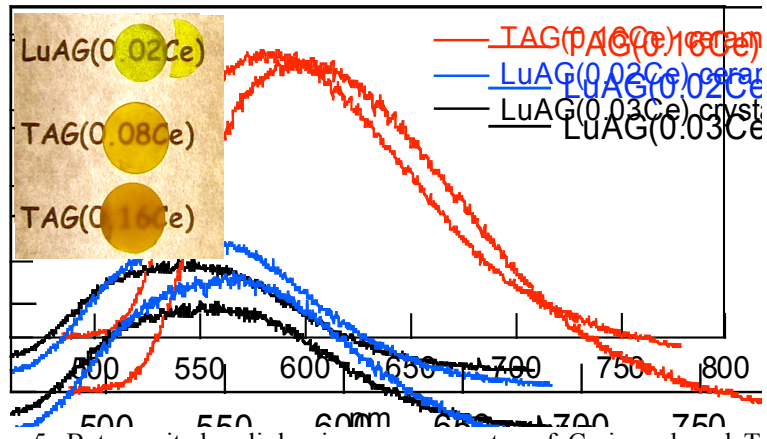

Fig. 5. Beta-excited radioluminescence spectra of Cerium doped TAG and LuAG. Spectra have been corrected for sensitivity.

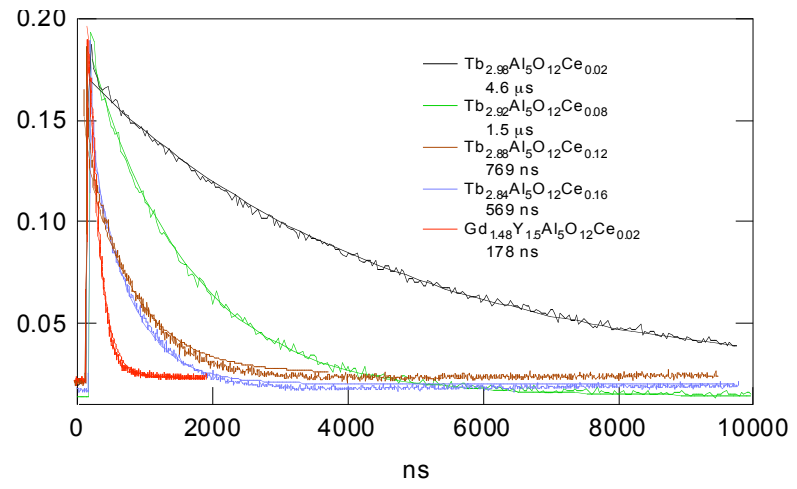

Fig. 6. Decay of $\mathrm{Ce}^{3+}$ in TAG becomes faster as a function of Ce-doping.

The radioluminescence spectrum of a $\mathrm{TAG}(\mathrm{Ce})$ ceramic $\left(\mathrm{Tb}_{3-\mathrm{x}} \mathrm{Al}_{5} \mathrm{O}_{12}: \mathrm{Ce}_{\mathrm{x}}, \mathrm{x}=0.16\right)$ exhibits much higher light yield (integrated over 30s) than that of $\mathrm{LuAG}(\mathrm{Ce})$, but its decay is slow. The slow principal decay of $\mathrm{Ce}^{3+}$ in TAG is thought to be the result of energy migration on $\mathrm{Tb}^{3+}$ sites. The principal decay reaches $<1 \mu$ s for $\mathrm{Ce}$ atomic fraction $\mathrm{x}>0.12$. Figure 6 shows decay times of TAG with varying concentrations of

$\mathrm{Ce}^{3+}$ obtained by direct excitation with a $266 \mathrm{~nm} \mathrm{Nd:YAG}$ laser (20 ns pulsewidth). While the measured beta-excited integral light yields for LuAG:Ce and TAG:Ce are high (30,000 and 80,000 Photons/MeV, respectively), some long decay components do not contribute to the scintillation light pulse measured in the pulse height spectra [14].

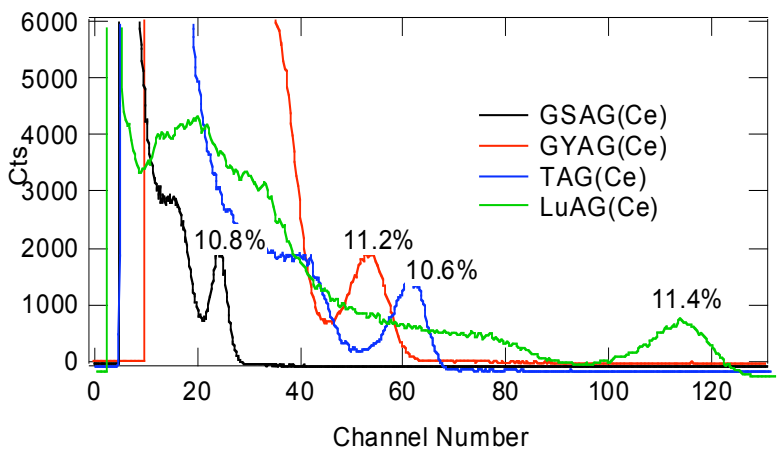

Fig. 7. Pulse-height spectra of garnet ceramics acquired at $662 \mathrm{keV}$.

\section{B. Gadolinium Garnets}

Since Gadolinium Aluminum Garnet, $\mathrm{Gd}_{3} \mathrm{Al}_{5} \mathrm{O}_{12}$, is thermodynamically unstable, due to the large mismatch in atomic radii for $\mathrm{Gd}$ and $\mathrm{Al}$. Therefore, we fabricated stabilized structures, incorporating the intermediate sized species, $\mathrm{Y}$ and Sc, GYAG $\left(\mathrm{Gd}_{1.5} \mathrm{Y}_{1.5} \mathrm{Al}_{5} \mathrm{O}_{12}: \mathrm{Ce}\right)$ and GSAG $\left(\mathrm{Gd}_{3} \mathrm{Sc}_{2} \mathrm{Al}_{3} \mathrm{O}_{12}: \mathrm{Ce}\right)$. We found that the beta-excited luminescence of GYAG was very high $(\sim 100,000 \mathrm{Ph} / \mathrm{MeV})$. Similar to TAG, the light yield of GYAG is thought to be enhanced by energy migration between the $\mathrm{Gd}^{3+}$ ions, again leading to some delayed luminescence components; this effect is less pronounced for the Gd-based garnets as the principal decay times for GYAG(Ce) and $\mathrm{GSAG}(\mathrm{Ce})$, even with only 0.03 atomic fraction Ce-doping, are in the 100-200 ns range (see Figure 6). However, we could not achieve transparency with GYAG (due to the typical presence of a small amount of perovskite $\mathrm{GdAlO}_{3}$ secondary phase, which produces scatter due to refractive index mismatch, even at $1 \%$ levels). In contrast, GSAG produced only a moderate light yield $(20,000$ $\mathrm{Ph} / \mathrm{MeV}$ ), but formed perfect pure phase garnet with excellent transparency. Pulse height measurements, shown in Figure 7,

TABLE III

SCINTILLATION PROPERTIES OF GARNETS, COMPARED TO CESIUM IODIDE

\begin{tabular}{llll}
\hline \hline Scintillator & $\begin{array}{c}\beta \mathrm{LY} \\
(\mathrm{Ph} / \mathrm{MeV})\end{array}$ & $\begin{array}{c}\gamma \mathrm{LY} \\
(\mathrm{Ph} / \mathrm{MeV})\end{array}$ & $\begin{array}{l}\text { Resolution } \\
\text { at } 662 \mathrm{keV}\end{array}$ \\
\hline GYAG:Ce ceramic & $>80,000$ & 16,500 & $11.2 \%$ \\
& & & \\
GSAG:Ce ceramic & 20,000 & 7,500 & $10.8 \%$ \\
TAG:Ce ceramic & 80,000 & 19,500 & $10.6 \%$ \\
YAG:Ce ceramic & 40,000 & 30,000 & $7.3 \%$ \\
LuAG:Ce ceramic & 30,000 & 20,000 & $11.4 \%$ \\
LuAG:Ce, Single crystal & 30,000 & 28,000 & $8.6 \%$ \\
CsI(Tl), Single crystal & 65,000 & 65,000 & $5.8 \%$ \\
\hline \hline
\end{tabular}


were acquired using a Hamamatsu R329EGP PMT as described in Section II.B.

In our attempts to retain the high light yield of GYAG, but attain phase purity, we subsequently worked on small additions of scandium to GYAG, as $\mathrm{Gd}_{1.5} \mathrm{Y}_{1.5} \mathrm{Sc}_{\mathrm{x}} \mathrm{Al}_{5-\mathrm{x}} \mathrm{O}_{12}$ (in all cases $\mathrm{Ce}=0.03$ atomic fraction substituting equally for $\mathrm{Gd}$ and $\mathrm{Y}$ ) and found that acceptable transparency can be achieved with as little as $\mathrm{Sc}=0.12$ (Figure 7).
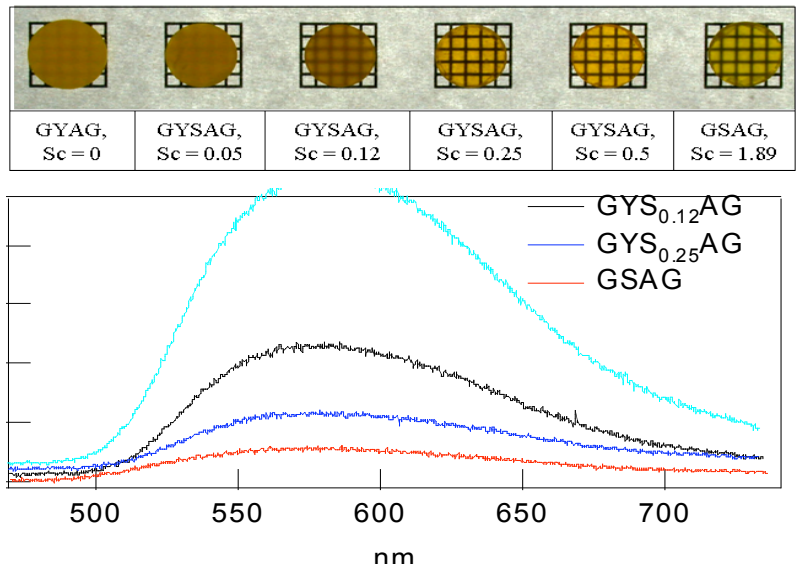

Fig. 8. Beta-excited radioluminescence spectra of Cerium doped Gadoliniumbased garnet ceramics. Spectra have been corrected for sensitivity.

In summary, we find that energy resolution for garnet ceramics matches performance of single crystals of the same materials, as reported for YAG by Yanagida, et al. [19] though the green-red luminescence of $\mathrm{Ce}^{3+}$ in the garnet host is a poor match to bi-alkali PMTs. Gd-based garnets have a faster primary decay $(<200 \mathrm{~ns})$ than Tb-based garnets. Energy migration enhances the integrated light yield of Tb- and Gdbased garnets $(80,000-100,000 \mathrm{Ph} / \mathrm{MeV})$, however, the "useful" prompt luminescence (able to be integrated within a $12 \mu$ s shaping time) is a fraction of the total. Work is underway to simultaneously optimize the composition for high prompt light yield and transparency.

\section{SCINTILLATION LIGHT YIELD NON- PROPORTIONALITY}

\section{A. The Scintillation Light Yield Non-proportionality Characterization Instrument}

The gamma ray energy resolution of scintillators is typically worse than the limit imposed by counting statistics. This degradation is understood as a material-dependent quantity, referred to as light yield to non-proportionality, whereby the light yield (photons per $\mathrm{MeV}$ ) is not actually a constant, but depends on the energy of the primary electron excited by the incident gamma ray. The SLYNCI ("scintillation light yield non-proportionality characterization instrument") is a unique facility that has been set up to measure the non-proportionality of scintillator materials, and learn about underlying

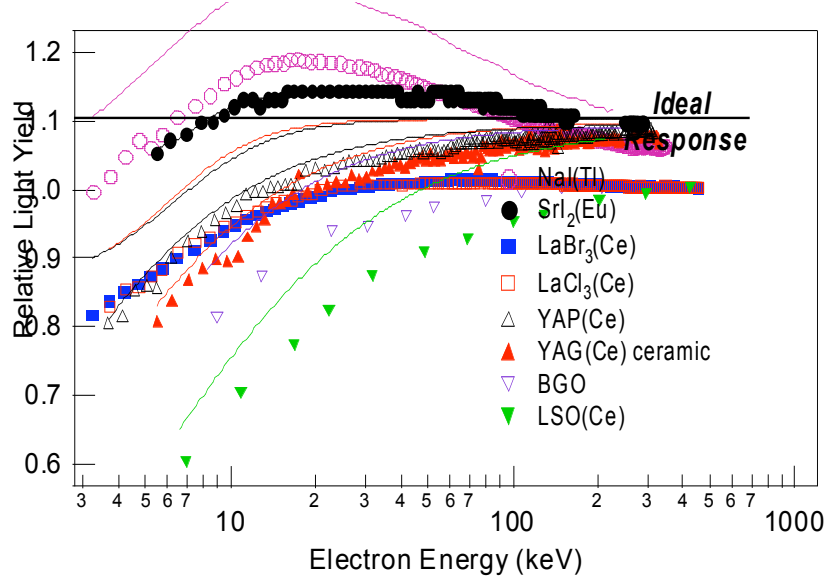

Fig. 9. Scintillation light yield proportionality data acquired for a variety of scintillator materials. All data acquired with SLYNCI except BGO and LSO, from Ref. 20.

scintillation mechanisms $[21,22]$. Figure 9 shows the relative light yield as a function of electron energy for $\mathrm{NaI}(\mathrm{Tl}), \mathrm{SrI}_{2}(\mathrm{Eu}$ $\mathrm{LaBr}_{3}(\mathrm{Ce}), \mathrm{LaCl}_{3}(\mathrm{Ce}), \mathrm{YAP}(\mathrm{Ce})$ and $\mathrm{YAG}(\mathrm{Ce})$ ceramic, acquired with the SLYNCI.

\section{B. Prediction of Energy Resolution}

Analysis of the SLYNCI data permits estimation of the contribution of the intrinsic electron non-proportionality of materials to energy resolution, as shown in Table IV. While the calculated values differ from the literature values, the rank ordering is good. Among the scintillators shown in Figure 9, only $\mathrm{SrI}_{2}(\mathrm{Eu}), \mathrm{LaCl}_{3}(\mathrm{Ce})$ and $\mathrm{LaBr}_{3}(\mathrm{Ce})$ offer the possibility of attaining $2 \%$ energy resolution. The light yield proportionality is excellent for $\operatorname{SrI}_{2}(0.5 \% \mathrm{Eu})$, and thus the contribution to energy resolution due to non-proportionality, $\sim 1.3 \%$ is small for $\operatorname{SrI}_{2}(\mathrm{Eu})$. This may be due to extremely efficient capture of excitation on the activator $\left(\mathrm{Eu}^{2+}\right)$ sites, compared to other scintillators. In contrast, the $2.7-3.7 \%$ estimated non-proportionality contribution to energy resolution for $\mathrm{YAG}(\mathrm{Ce})$ may preclude the use of garnets in high resolution gamma ray spectroscopy, although the nonproportionality for Gd-containing compounds might be more favorable by virtue of energy migration on the Gd sub-

TABLE IV

INTRINSIC NON-PROPORTIONALITY CONTRIBUTION TO ENERGY RESOLUTION FOR SEVERAL CRYSTALS

\begin{tabular}{lllll}
\hline \hline Scintillator & $\begin{array}{l}\mathrm{R}_{\text {NonP }} \\
\text { calculated }\end{array}$ & $\begin{array}{l}\mathrm{R}_{\text {NonP }} \\
\text { literature }\end{array}$ & $\begin{array}{l}\text { Light Yield } \\
(\mathrm{Ph} / \mathrm{MeV})\end{array}$ & $\begin{array}{l}\mathrm{R}_{\text {Tot }} \\
\text { literature }\end{array}$ \\
\hline $\mathrm{LaCl}_{3}(\mathrm{Ce})$ & $2.0 \%$ & $1.4 \%^{\mathrm{a}}$ & 49,000 & $3.1 \%^{\mathrm{a}}$ \\
$\mathrm{SrI}_{2}(\mathrm{Eu})$ & $2.1 \%$ & $1.3 \%$ (est. $^{\mathrm{b}}$ & 115,000 & $2.8 \%^{\mathrm{b}}$ \\
$\mathrm{LaBr}_{3}(\mathrm{Ce})$ & $2.4 \%$ & $1.6 \%^{\mathrm{a}}$ & 60,000 & $2.6 \%^{\mathrm{a}}$ \\
$\mathrm{YAP}(\mathrm{Ce})$ & $2.3 \%$ & $4.4 \%^{\mathrm{c}}$ & 17,000 & $7.2 \%^{\mathrm{c}}$ \\
$\mathrm{YAG}(\mathrm{Ce})$ & $2.7 \%$ & $3.7 \%$ (est. $^{\mathrm{b}}$ & 30,000 & $7.3 \%^{\mathrm{b}}$ \\
$\mathrm{BGO}$ & $3.4 \%$ & $3.9 \%^{\mathrm{c}}$ & 9,000 & $7.8 \%^{\mathrm{c}}$ \\
$\mathrm{NaI}(\mathrm{Tl})$ & $4.5 \%$ & $5.7 \%^{\mathrm{c}}$ & 40,000 & $6.5 \%^{\mathrm{c}}$ \\
$\mathrm{LSO}(\mathrm{Ce})$ & $6.3 \%$ & $6.6 \%^{\mathrm{c}}$ & 23,000 & $7.9 \%^{\mathrm{c}}$ \\
\hline${ }^{\mathrm{a}} \mathrm{Ref.} 28$ & & & \\
${ }^{\mathrm{b}} \mathrm{This}$ work & & & & \\
${ }^{\mathrm{c}} \mathrm{Ref.} 29$ & & &
\end{tabular}


lattice.

A detailed treatment of the factors contributing to scintillator energy resolution, and the methods for calculating the non-proportionality contribution to resolution (as listed in Table IV) follows. The overall efficiency of a scintillator detector, $\eta_{\mathrm{SCINT}}$, is the product of efficiencies of the generation of carriers during the cascade, $\eta_{\mathrm{GEN}}$, capture of electrons and holes at the activators, $\eta_{\mathrm{CAP}}$, quantum yield of emission of the activator, $\eta_{\mathrm{QY}}$, and collection and detection of the photons by the photodetector, $\eta_{\mathrm{C} \& \mathrm{D}}$ :

$\eta_{\mathrm{SCINT}}=\eta_{\mathrm{GEN}} \eta_{\mathrm{CAP}} \eta_{\mathrm{QY}} \eta_{\mathrm{C} \& \mathrm{D}}$

The number of photons detected is $N_{P E}=\eta_{\operatorname{SCINT}}\left(E_{\gamma} / E_{g}\right)$, where $E_{\gamma}$ is the gamma energy, and $E_{g}$ is the bandgap of the scintillator. The sum of the variances provides the total variance in the scintillator detector:

$$
\begin{aligned}
& \left(\delta \eta_{\mathrm{SCINT}} / \eta_{\mathrm{SCINT}}\right)^{2}=\left(\delta \eta_{\mathrm{GEN}} / \eta_{\mathrm{GEN}}\right)^{2}+\left(\delta \eta_{\mathrm{CAP}} / \eta_{\mathrm{CAP}}\right)^{2} \\
& +\left(\delta \eta_{\mathrm{QY}} / \eta_{\mathrm{QY}}\right)^{2}+\left(\delta \eta_{\mathrm{C} \& \mathrm{D}} / \eta_{\mathrm{C} \& \mathrm{D}}\right)^{2}
\end{aligned}
$$

where $\left(\delta \eta_{\mathrm{GEN}} / \eta_{\mathrm{GEN}}\right)^{2}=\left(\mathrm{FE}_{\gamma} / \beta \mathrm{E}_{\mathrm{g}}\right)$ for $\mathrm{F}=$ Fano factor (usually $\sim 0.1), \beta \sim 2.5-3 ;\left(\delta \eta_{\mathrm{C \& D}} / \eta_{\mathrm{C \& D}}\right)^{2}=\left[\left(1-\eta_{\mathrm{C \& D}}\right) /\right.$ $\left[\eta_{C \& D} \eta_{\text {CAP }} \eta_{\mathrm{QY}}\left(\mathrm{E}_{\gamma} / \beta \mathrm{E}_{\mathrm{g}}\right)\right]$ for binomial statistics (which generalizes the usual Poisson statistics to high $\eta_{\text {C\&D }}$ values); and the variance in quantum yield is taken as zero, since $\eta_{\mathrm{QY}}=$ 1 for the materials of interest here. The photodetector noise term is customarily added ad hoc as $\left(\mathrm{N}_{\mathrm{NOISE}} / \eta_{\mathrm{SCINT}} \mathrm{E}_{\gamma}\right)^{1 / 2}$, where $\mathrm{N}_{\mathrm{NOISE}}$ is the number of noise photoelectrons detected, and is summed in quadrature with the rest of the terms in Eq. (2). Our premise is that the electron non-proportionality resides in the $\left(\delta \eta_{\mathrm{CAP}} / \eta_{\mathrm{CAP}}\right)$ term, as described below. The socalled gamma nonproportionality would constitute an additional contribution, not considered here.

The electron non-proportionality is caused by the fluctuations in the stopping power, $\mathrm{dE} / \mathrm{dx}$, which in turn causes fluctuations in the carrier and exciton densities generated by the high-energy electron in the scintillator. We can describe the variation in the carrier capture efficiency in terms of the variation in $\mathrm{dE} / \mathrm{dx}$ by recasting the second term of Eq. (2) as:

$\delta \eta_{\mathrm{CAP}} / \eta_{\mathrm{CAP}}=\left(1 / \eta_{\mathrm{CAP}}\right)\left[\mathrm{d} \eta_{\mathrm{CAP}} / \mathrm{d}(\mathrm{dE} / \mathrm{dx})\right] \delta(\mathrm{dE} / \mathrm{dx})$

We need to deduce the analytical forms for the capture efficiency, $\eta_{\mathrm{CAP}}$, and for the variation in the stopping power, $\delta(\mathrm{dE} / \mathrm{dx})$. The Birks [30] and Onsager [31] formulae are used to describe our mechanism whereby excitons are created (Onsager, Ons) and annihilated (Birks, B):

$\eta_{\mathrm{CAP}}=\eta_{\mathrm{CAP}}^{0}\left\{1-\eta_{\text {Ons }} \exp \left[-\mathrm{a}_{\text {Ons }}(\mathrm{dE} / \mathrm{dx})\right]\right\} /\left[1+\mathrm{a}_{\mathrm{B}}(\mathrm{dE} / \mathrm{dx})\right]$

where $a_{B}$ is the Birks parameter and $\eta_{O n}$ and $a_{O n}$ are the Onsager parameters. Briefly stated, the well-known Onsager mechanism describes the formation of excitons or the capture of both electrons and holes at an activator, while the also well- known Birks formulation accounts for the exciton-exciton annihilation. The stopping power is obtained with the BetheBloch equation, which has been modified to more accurately describe the low energy regime with an additional constant $\left(c_{1}\right)[32]:$

$(\mathrm{dE} / \mathrm{dx})=\left(2 \pi \mathrm{e}^{4} \rho_{\mathrm{e}} / \mathrm{E}\right) \ln \left\{(2.71 / 2)^{1 / 2}\left[\left(\mathrm{E}+\mathrm{c}_{1} \mathrm{I}\right) / \mathrm{I}\right]\right\}$

where I is the average ionization energy, (a quantity which is obtained from the NIST web-site), $e$ is the elemental electron charge, $\rho_{\mathrm{e}}$ is the electron density of the material, and $\mathrm{E}$ is the electron energy. Eq. (5) reveals that the largest stopping power is evoked at the lowest electron energies (by way of the $1 / \mathrm{E}$ dependence). The fluctuations in stopping power are described with Landau's distribution (an analysis well-known within the high-energy physics community [30], however applied to scintillators for the first time here):

$\delta(d E / d x)=2 \pi e^{4} \rho_{e} /\left(E+c_{2} I\right)$

Here we again face the difficulty of this equation being intended for circumstances for which $\mathrm{E}>\mathrm{I}$, suggesting that we add the additional " $\mathrm{c}_{2} \mathrm{I}$ " term in the denominator $(\mathrm{E} \rightarrow \mathrm{E}+$ $\mathrm{c}_{2} \mathrm{I}$ ). The standard equations for stopping power (Bethe) and for Landau fluctuations were both originally intended for large values of $\mathrm{E}$, requiring that the $\mathrm{cI}$ terms be added with $\mathrm{c}_{1}$ and $\mathrm{c}_{2}$ serving as additional fitting parameters; perhaps future theories can account for the low energy behavior more rigorously.
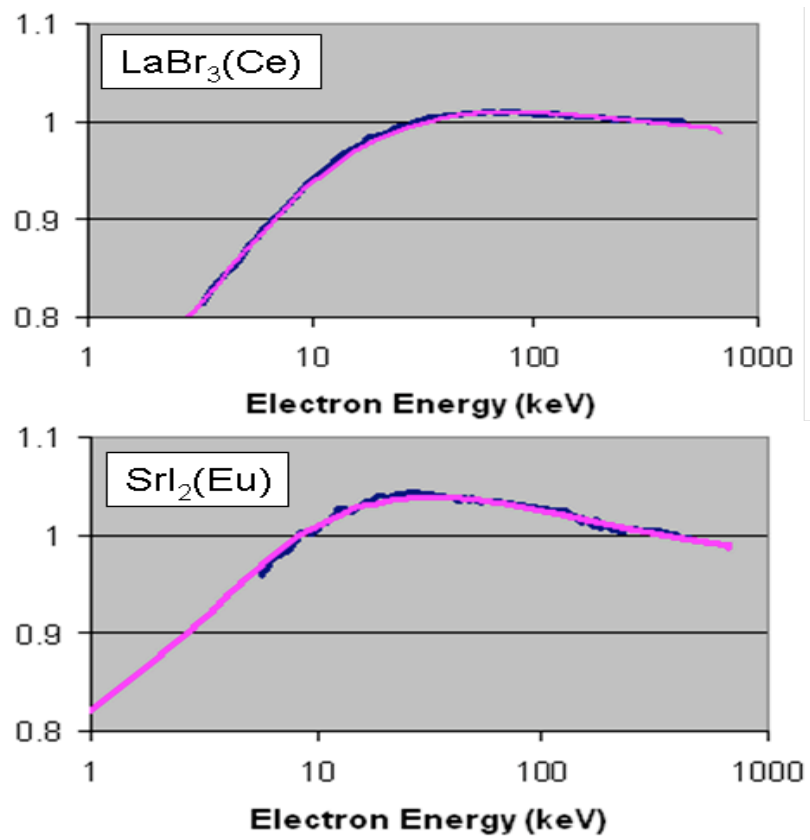

Fig. 10. Fits to $\mathrm{LaBr}_{3}(\mathrm{Ce})$ and $\mathrm{SrI}_{2}(\mathrm{Eu}) \mathrm{SLYNCI}$ data, using $\mathrm{c}_{1}=2.8$.

Next, the square of the variances must be summed along the trajectory $(\mathrm{T})$ of the electron from its initial energy $\mathrm{E}_{\mathrm{O}}$ to the ionization energy I to find the contribution to the resolution:

$\mathrm{R}_{\mathrm{NonP}}=3.6\left(\delta \eta_{\mathrm{CAP}} / \eta_{\mathrm{CAP}}\right)_{\mathrm{T}}=$
$\left.3.6\left\{\int_{\mathrm{Eo}} \mathrm{I}\left(\delta \eta_{\mathrm{CAP}} / \eta_{\mathrm{CAP}}\right)^{2} \mathrm{dE}\right\} / \mathrm{E}_{0}\right\}^{1 / 2}$ 
where the 3.6 factor is added to convert the variances to a FWHM contribution to the resolution by directing plotting the Landau function [33] and observing the width. We have carefully evaluated fits to $\mathrm{LaBr}_{3}(\mathrm{Ce})$ and $\mathrm{SrI}_{2}(\mathrm{Eu})$, shown in Figure 10, and many other scintillators and determined the optimal magnitude of the $c_{l}$ parameter to be 2.8. Similarly, fitting the observed contributions to the non-proportionality for numerous scintillators yields $c_{2}=1.5$.

The $\eta_{\text {Ons }}$ values reveal that $\eta_{\text {Ons }}=16-20 \%$ of electrons and holes can subsequently attracted to each other after the cascade is complete, and then transfer their energy to activators that emit. The finding that $a_{\text {Ons }}>a_{B}$ implies that higher stopping is at first beneficial for activation as we pass to lower electron energy (causing a rise in light yield), but also that at the highest stopping power (i.e. lowest electron energy) exciton-exciton annihilation leads to the precipitous drop in light yield.

\section{LeVERAGING Optical Design to IMPROVE ENERGY RESOLUTION}

The effect of scintillator geometry, surface finish and the choice of wrapping material are important in the uniformity and magnitude of light collection from the scintillator to the photodetector. We used the ray trace code Detect2000 to study the light collection efficiency of many shapes, including sphere, cube, cone, cylinder and tapered cylinder, and found that the tapered cylinder geometry can be used to increase light collection efficiency. In addition, we identified an improved, "wrappable" Teflon-based reflector material, Gore DRP, which exhibits superior uniformity and reflectivity compared to standard Teflon tape [14]. As an example of the effect of surface finish and wrapping conditions, we studied how the energy resolution at $662 \mathrm{keV}$ acquired with a Hamamatsu R980 bialkali PMT and $8 \mu$ s shaping time for Bismuth Germanate (BGO) varies with wrapping. The improvement in light collection with a tapered vs. cylindrical BGO crystal was reported earlier [14]. Figure 11 shows how the energy resolution of a tapered cylinder of BGO with a ground surface improves from $11.6 \%$ to $8.1 \%$ by wrapping with 6 layers of Teflon tape, and then improves further by adding a backing layer of $3 \mathrm{M} \mathrm{VM} 2000$ to $7.8 \%$. The point is that achieving $2 \%$ resolution will require careful attention to the optics and electronics, as well as a superb scintillator material.

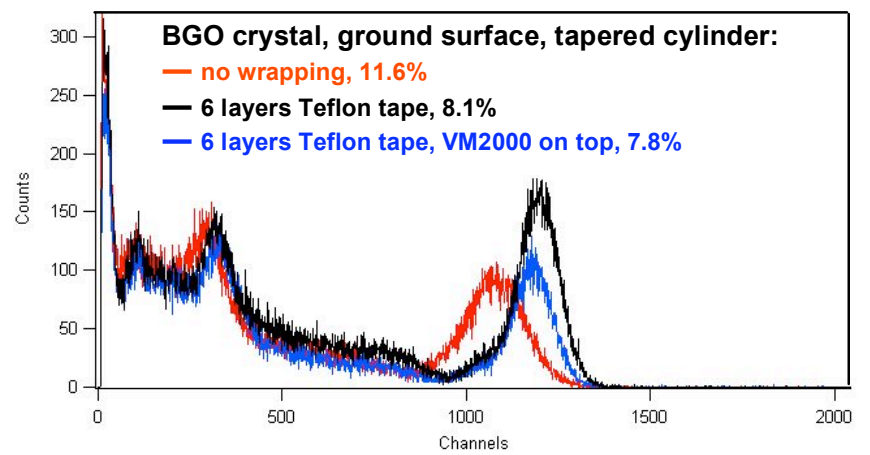

Fig. 11. Energy resolution and light collection are improved for a BGO crystal shaped into a tapered cylinder with a ground surface, then wrapped with diffuse reflecting Teflon, and finally a backing layer of 3M VM2000.

\section{Summary}

We have identified scintillator candidates through a "directed search" methodology. Among them, the most growable, highest light yield, and most proportional material is Strontium Iodide doped with Europium. Transparent ceramics are a new class of scintillators with several offering extremely high light yields, but delayed luminescence and intrinsic non-proportionality may limit their applicability for radioisotope identification gamma ray detectors. Among the scintillators characterized for light yield proportionality, $\mathrm{SrI}_{2}(\mathrm{Eu}), \mathrm{LaCl}_{3}(\mathrm{Ce})$ and $\mathrm{LaBr}_{3}(\mathrm{Ce})$ offer potential to achieve $2 \%$ resolution. Optimization of the optics and careful detector engineering is likely to make this goal a reality over the next few years.

\section{REFERENCES}

[1] E. V. D. van Loef, P. Dorenbos, C. W. E. van Eijk, K. Kramer, H. U. Gudel, "High-energy-resolution scintillator: $\mathrm{Ce}^{3+}$ activated $\mathrm{LaBr}_{3}$ ", Appl. Phys. Lett, vol.79, p. 1573, 2001.

[2] K.S. Shah, J. Glodo, M. Klugerman, W.M. Higgins, T. Gupta, P. Wong, IEEE Trans. Nucl. Sci. vol. 51, p. 2395, 2004.

[3] C. Fiorini, A. Gola, M. Zanchi, A. Longoni, P. Lechner, H. Soltau, L. Strüder, IEEE Trans. Nucl. Sci. vol. 53, p. 2392, 2006.

[4] R. Hofstadter, E. W. O’Dell, and S. T. Schmidt, IEEE Trans. Nucl. Sci. NS-11, p. 12, 1964.

[5] N.J. Cherepy, G. Hull, A. Drobshoff, S.A. Payne, E. van Loef, C. Wilson, K. Shah, U.N. Roy, A. Burger, L.A. Boatner, W-S Choong, W.W. Moses "Strontium and Barium Iodide High Light Yield Scintillators," Appl. Phys. Lett. vol. 92, p. 083508, 2008.

[6] E. V. D. van Loef, C. M. Wilson N. J. Cherepy, G Hull, S. A. Payne, W. S. Choong, W. W. Moses, K. S. Shah, "Crystal Growth and Scintillation Properties of Strontium Iodide Scintillators", these proceedings.

[7] N.J. Cherepy, G. Hull, T.R. Niedermayr, A. Drobshoff, S.A. Payne, U.N. Roy, Y. Cui, A. Bhattacharaya, M. Harrison, M. Guo, M. Groza, A. Burger, "Barium iodide single-crystal scintillator detectors," Proc. SPIE, vol. 6706, p. 670616, 2007.

[8] J. Selling, M. D. Birowosuto, P. Dorenbos, S. Schweizer, J. Appl. Phys., vol. 101, p.034901, 2007.

[9] R. Hofstadter, "Europium-activated Strontium Iodide Scintillators," US Patent 3,373,279, 1968 .

[10] E.V. van Loef, W.M. Higgins, J. Glodo, A.V. Churilov, K.S. Shah "Crystal growth and characterization of rare earth iodides for scintillation detection," J. Crystal Growth vol. 310, p. 2090, 2008.

[11] R. Hawrami, M.D. Aggarwal, U.N. Roy, M. Groza, Y. Cui, A. Burger, N. Cherepy, S.A. Payne, "New Scintillator Materials $\mathrm{K}_{2} \mathrm{CeBr}_{5}$ and $\mathrm{Cs}_{2} \mathrm{CeBr}_{5}$ " J. Crystal Growth, vol. 310, p. 2099, 2008.

[12] E. V. D. van Loef, J. Glodo, W. M. Higgins, and K. S. Shah, "Optical and Scintillation Properties of $\mathrm{Cs}_{2} \mathrm{LiYCl}_{6}: \mathrm{Ce}^{3+}$ and $\mathrm{Cs}_{2} \mathrm{LiYCl}_{6}: \mathrm{Pr}^{3+}$ Crystals," IEEE Trans. Nucl. Sci., 52, 1819, 2005.

[13] E. V. van Loef, W.M. Higgins, J. Glodo, C. Brecher, A. Lempicki, V. Venkataramani, W.W. Moses, S.E. Derenzo, and K.S. Shah Scintillation Properties of $\mathrm{SrHfO}_{3}: \mathrm{Ce}^{3+}$ and $\mathrm{BaHfO}_{3}: \mathrm{Ce}^{3+}$ Ceramics IEEE Trans. Nucl. Sci., vol. 54, p. 741, 2007.

[14] G. Hull, J.J. Roberts, J.D. Kuntz, S.E. Fisher, R.D. Sanner, T.M. Tillotson, A.D. Drobshoff, S.A. Payne, and N.J. Cherepy, "Ce-doped single crystal and ceramic garnets for $\gamma$ ray detection" Proc. SPIE vol. 6706, p. 670617, 2007

[15] J.D. Kuntz, J.J. Roberts, M. Hough, N.J. Cherepy "Multiple Synthesis Routes to Transparent Ceramic Lutetium Aluminum Garnet," Scripta Mat., vol. 57, p. 960, 2007.

[16] N. Cherepy, J. Kuntz, T. Tillotson, D. Speaks, S.A. Payne, B. Chai, "Single Crystal and Transparent Ceramic Lutetium Aluminum Garnet Scintillators," Nucl. Instr. Meth. A, vol. 579, p. 38, 2007.

[17] J.A. Mares, A. Beitlerova, M. Nikl, N. Solovieva, C. D'Ambrosio, K.Blazek, P. Maly, K. Nejezchleb, F. de Notaristefan, "Scintillation response of Ce-doped or intrinsic scintillating crystals in the range up to $1 \mathrm{MeV}, "$ Radiation Measurements vol. 38, p.353, 2004. 
[18] A. Kling et al., "Scintillation properties of cerium-doped gadoliniumscandium-aluminum garnets", Nucl. Instr. \& Meth. A vol. 346, p.205, 1994.

[19] T.Yanagida, H. Takahashi, T. Ito, D. Kasama, T. Enoto, M. Sato, Sh. Hirakuri, M. Kokubun, K. Makishima, T. Yanagitani, H. Yagi, T. Shigeta, T. Ito "Evaluation of Properties of YAG (Ce) Ceramic Scintillators," IEEE Trans. Nucl. Sci., vol. 52, p. 1836, 2005.

[20] W.-S. Choong, K.M. Vetter, W.W. Moses, S.A. Payne, N.J. Cherepy, J.D. Valentine and G. Hull, "Design of a Facility for Measuring Scintillator Non-Proportionality," IEEE Trans. Nucl. Sci., vol. 55, p. $1753,2008$.

[21] W.-S. Choong, G. Hull, W.W. Moses, K.M. Vetter S.A. Payne, N.J. Cherepy, J.D. Valentine, "Performance of a Facility for Measuring Scintillator Non-Proportionality," IEEE Trans. Nucl. Sci., vol. 55, p. 1073, 2008.

[22] G. Hull, S. Du, T. Niedermayr, S. Payne, N. Cherepy, A. Drobshoff, and L. Fabris "Light Collection Optimization in Scintillator Based GammaRay Spectrometers" Nucl. Instr. Meth. A, vol. 588, p. 384 (2008).

[23] Taulbee, T.D.; Rooney, B.D.; Mengesha, W.; Valentine, J.D, "The measured electron response nonproportionalities of $\mathrm{CaF}_{2}, \mathrm{BGO}$, and LSO,” IEEE Trans. Nucl. Sci., vol. 44, p. 489, 1997.

[24] E. T. Rietschel, H. Bärnighausen "Die Kristallstruktur von Strontiumjodid $\mathrm{SrJ}_{2}$ ", Z. Anorg. Allg. Chem., vol. 368, p. 62, 1969.

[25] Von Bärnighausen, N. Schultz, Acta Cryst. B25, p. 1104, 1969.

[26] D. Singh, "Near optical isotropy in noncubic SrI2: Density functional calculations," Appl. Phys. Lett. vol. 92, p. 201908, 2008.

[27] J.J. Roberts, N.J. Cherepy, J.D. Kuntz, "Method for Fabrication of Transparent Ceramics using Nanoparticles Synthesized via Flame Spray Pyrolysis," IL-11752, (patent application filed Oct. 2007).

[28] Kramer KW, Dorenbos P, Gudel HU, van Eijk CWE "Development and characterization of highly efficient new cerium doped rare earth halide scintillator materials," J. Mater. Chem. vol. 16, p. 2776, 2003.

[29] P. Dorenbos. J. T. M. de Haas, and C. W. E. van Eijk, "NonProportionality in the Scintillation Response and the Energy Resolution Obtainable with Scintillation Crystals," IEEE Trans. Nucl. Sci., vol. 42, p.2190, 1995.

[30] J. B. Birks, Theory and Practice of Scintillation Counting (Pergamon Press, Oxford, 1964).

[31] For example, see Eq. 27 of G. J. Hoffman and A. C. Albrecht, "Near threshold photoionization spectra in nonpolar liquids: A geminate pair based model," J. Phys. Chem. vol. 95, p. 2231, 1991.

[32] A. Jablonski, S. Tanuma, and C. J. Powell, "New universal expression for the electron stopping power for energies between $200 \mathrm{eV}$ and 30 keV," Surface and Interface Analysis vol. 38, p. 76, 2006.

[33] J. E. Moyal, "Theory of ionization fluctuations," Philosophical Magazine vol. 46, p. 263, 1955. 